\section{BMJ Paediatrics Open}

\title{
Adverse events associated with paediatric massage therapy: a systematic review
}

Mohammad Karkhaneh, ${ }^{1}$ Liliane Zorzela (D) , ${ }^{2}$ Hsing Jou, ${ }^{1}$ Martha Funabashi, ${ }^{1}$ Trish Dryden, ${ }^{3}$ Sunita Vohra ${ }^{1,2}$

To cite: Karkhaneh M, Zorzela L, Jou H, et al. Adverse events associated with paediatric massage therapy: a systematic review. BMJ Paediatrics Open 2020;4:e000584. doi:10.1136/ bmjpo-2019-000584

- Additional material is published online only. To view please visit the journal online (http://dx.doi.org/10.1136/ bmjpo-2019-000584).

Received 3 0ctober 2019 Revised 13 March 2020 Accepted 17 March 2020
Check for updates

(c) Author(s) (or their employer(s)) 2020. Re-use permitted under CC BY-NC. No commercial re-use. See rights and permissions. Published by BMJ.

${ }^{1}$ Medicine, University of Alberta, Edmonton, Alberta, Canada ${ }^{2}$ Pediatrics, University of Alberta, Edmonton, Alberta, Canada ${ }^{3}$ Research and Corporate Planning, Centennial College, Toronto, Ontario, Canada

Correspondence to Dr Sunita Vohra; svohra@ ualberta.ca

\section{ABSTRACT}

Introduction Massage therapy (MT) is frequently used in children. No study has systematically assessed its safety in children and adolescents. We systematically review adverse events (AEs) associated with paediatric MT. Methods We searched seven electronic databases from inception to December 2018. We included studies if they (1) were primary studies published in a peer-reviewed journal, (2) involved children aged 0-18 years and (3) a type of MT was used for any indication. No restriction was applied to language, year of publication and study design. AEs were classified based on their severity and association to the intervention.

Results Literature searches identified 12286 citations, of which 938 citations were retrieved for full-text evaluation and 60 studies were included. In the included studies, $31(51.6 \%)$ did not report any information on AEs, $13(21.6 \%)$ reported that no AE occurred and 16 studies $(26.6 \%)$ reported at least one AE after MT. There were 20 mild events (grade 1) that resolved with minimal intervention, 26 moderate events (grades 2-3) that required medical intervention, and 18 cases of severe AEs (grades 4-5) that resulted in hospital admission or prolongation of hospital stay; of these, $17 \mathrm{AEs}$ were volvulus in premature infants, four of which were ultimately fatal events.

Conclusion We identified a range of AEs associated with MT use, from mild to severe. Unfortunately, the majority of included studies did not report if an AE occurred or not, leading to publication bias. This review reports an association between abdominal massage with volvulus without malrotation in preterm infants; it is still to be defined if this is casual or not, but our findings warrant caution in the use of abdominal massage in preterm infants.

\section{BACKGROUND}

Massage therapy (MT) is one of the most popular complementary therapies in North America and has a long history of practice. ${ }^{12}$ According to the College of Massage Therapists of Ontario, "Massage therapy consists primarily of hands-on manipulation of the soft tissues of the body, specifically, the muscles, connective tissue, tendons, ligaments and joints for the purpose of optimizing health. Massage therapy treatment has a therapeutic

\section{What is known about the subject?}

Massage therapy (MT) has been widely used for many different indications in children and adults.

- Several studies report its efficacy, but adverse events (AEs) of massage therapy are poorly investigated.

\section{What this study adds?}

A range of AEs are associated with MT use, from mild to severe.

- There is an association between abdominal MT in preterm neonates and volvulus without malrotation, but the causality of this association is yet to be determined.

- Until further data are identified, extreme caution on the use of abdominal massage in preterm neonates is warranted.

effect on the body and optimizes health and well-being by acting on the muscular, nervous and circulatory systems."3

Massage therapists press, rub and manipulate muscles and soft tissues of the body, often with their hands and fingers, to relieve physical dysfunction and pain, reduce stress, promote relaxation, reduce anxiety or depression, and improve general well-being. ${ }^{45}$

Various types of MTs have been practised using specific techniques, including Swedish, Thai, shiatsu, tui na, connective tissue, deep tissue, myofascial, trigger point and so on. ${ }^{6-8}$

Massage is used in children around the world, including countries where massage is not part of their traditional medicine practices. Close to $1 \%$ of American children use MT. ${ }^{9}$ In Canada, a survey involving 979 families attending subspecialty clinics demonstrated that the most common complementary therapy reported was massage, with $39.1 \%$ reporting use. ${ }^{10}$ In Europe, the frequency of massage use varies from $8.7 \%$ to $29 \%$ in a subpopulation of children with oncological disorders. ${ }^{11} \mathrm{MT}$ is frequently used in children 
with health problems, and its use is as high as $47 \%$ in patients with neurological disorders, $38 \%$ in patients with cardiac disorders and $34 \%$ in patients with respiratory disorders. ${ }^{12-14}$

Despite MT's longstanding history and popularity, specific mechanisms by which massage exerts its therapeutic effects are not yet known. ${ }^{75-17}$ Researchers have long been interested in MT for children's health and well-being. ${ }^{18}$ A recent meta-analysis of clinical trials of MT on infants under 6 months of age found statistically significant effects on weight and height, improving head/arm/leg circumference, 24-hour sleep duration, lowering blood bilirubin level and frequency of diarrhoea. ${ }^{19}$ Among preterm infants, MT enhanced average weight gain and reduced hospital length of stay. ${ }^{20}$ In children 2-18 years old, MT has been shown to improve arthritis pain, muscle tone and decrease anxiety. ${ }^{21}$ There is limited evidence supporting MT for cancer pain ${ }^{22}$ and chronic pain in children. ${ }^{23}$

Most systematic reviews of paediatric MT have focused on the effectiveness of MT rather than its safety. ${ }^{18-21 ~ 24-30}$ One systematic review included two case reports of adverse events (AEs) among children ${ }^{83}$ : one infant with scrotal haematoma associated with MT of a hydrocoele ${ }^{32}$ and a teenager with a popliteal artery pseudoaneurysm after MT overlying an exostosis. ${ }^{33}$ AEs reported for adults were more diverse, including cerebrovascular accidents, disc herniation/spinal cord injury, thromboembolism (renal, pulmonary), soft tissue trauma, leg ulcer and genitourinary injuries. ${ }^{813435}$ These studies demonstrated that the nature and circumstances of MT AEs for adults are quite different from paediatrics. While many complementary therapies are considered to be at low risk of harm, safety of health interventions should be measured, rather than assumed, especially in vulnerable populations, including children. ${ }^{36} 37$

The objective of this systematic review was to identify the evidence of AEs associated with massage therapy in children.

\section{METHODS}

\section{Searching databases}

A systematic review was conducted according to the guidelines of the Preferred Reporting Items for Systematic Review (PRISMA) Statement and the PRISMA Harms. ${ }^{38}{ }^{39}$ In consultation with two massage therapists, a health research librarian designed a comprehensive search strategy. Seven electronic databases were searched from inception to December 2018. The databases included Medline, EMBASE, CINAHL, Cochrane Central Registry of Controlled Trials, Cochrane Database of Systematic Reviews, PsycINFO and Alt HealthWatch. We identified search terms by using keywords including Massage, Adverse Effects and Pediatrics, and a combination of subject terms selected from the controlled vocabulary or thesaurus (eg, MeSH-Medical Subject Headings,
Emtree for Embase, CINAHL Headings and PsycINFO Thesaurus) with a wide range of free-text terms.

No language restrictions were applied. The search strategy was adapted to follow recommendations by Golder and Loke to optimise for the retrieval of AEs data. ${ }^{40}$ The full Medline search strategy is available in online supplementary appendix A.

\section{Study selection}

Studies were eligible to be included if they (1) were a primary study published in a peer-reviewed journalprimary study was defined as "study reported directly by the researcher that conducted the study", rather than depending on data collected from previously done research; (2) involved children from birth to 18 years of age; and (3) used MT for any indication-studies were not excluded based on conditions leading to MT. The inclusion of studies was not limited by medical condition, training of massage provider or the presence/absence of a comparison/control intervention. There was no restriction by study design or reporting AE. We excluded studies if they (1) only applied light touch or (2) only used self-massage, and were (3) grey literature. Studies of reflexology and studies of massage for lacrimal duct obstruction were also excluded since those were not relevant to this review. Case reports were only included if they reported an AE. Two reviewers performed study selection, independent and in duplicate, and discrepancies were resolved by consensus or a third reviewer.

\section{Data extraction}

A structured data extraction form was used to collect data from the articles. General characteristics of studies included country, study design, settings, population, age and gender. Specific information included indication for treatment, $\mathrm{AE}$ severity, $\mathrm{N}$ of event, age (age/weight and age at AE for newborn babies), gender, type of MT, MT practitioner, outcome with severity grade and notes from the authors. Independent duplicate assessment was performed for both study selection and data extraction.

AEs were defined as per the Cochrane handbook as "adverse event is an unfavorable or harmful outcome that occurs during, or after, the use of a drug or other intervention, but is not necessarily caused by it". ${ }^{41}$

\section{Data synthesis}

The data from studies were tabulated into general information and AEs tables. The Common Terminology Criteria for Adverse Events (CTCAE) scale was used to classify severity of $\mathrm{AEs}^{42}$ (table 1 ).

The severity was categorised into five grades, from grade 1 (mild, asymptomatic) to grade 5 (death), based on information provided by the studies. Duplicate assessment of CTCAE ratings was performed and discrepancies between two reviewers were resolved by consulting a senior reviewer.

We also classified the AEs as 'direct', if directly caused by the intervention, or 'indirect', if the intervention 


\begin{tabular}{|c|c|}
\hline Grading & Description \\
\hline Grade 1 & $\begin{array}{l}\text { Mild; asymptomatic or mild symptoms; clinical } \\
\text { or diagnostic observations only; intervention } \\
\text { not indicated }\end{array}$ \\
\hline Grade 2 & $\begin{array}{l}\text { Moderate; minimal, local or non-invasive } \\
\text { intervention indicated; limiting age-appropriate } \\
\text { instrumental Activities of Daily Living } \\
\text { (instrumental ADL: preparing meals, shopping } \\
\text { for groceries or clothes, using the telephone, } \\
\text { managing money, etc) }\end{array}$ \\
\hline Grade 3 & $\begin{array}{l}\text { Severe or medically significant but not } \\
\text { immediately life-threatening; hospitalisation } \\
\text { or prolongation of hospitalisation indicated; } \\
\text { disabling; limiting self-care ADL (bathing, } \\
\text { dressing and undressing, feeding self, } \\
\text { using the toilet, taking medications and not } \\
\text { bedridden) }\end{array}$ \\
\hline Grade 4 & $\begin{array}{l}\text { Life-threatening consequences; urgent } \\
\text { intervention indicated }\end{array}$ \\
\hline Grade 5 & Death related to $A E$ \\
\hline
\end{tabular}

CTCAE, Common Terminology Criteria for Adverse Events.

caused a delay in diagnosis or treatment which resulted in an $\mathrm{AE}^{43}$

Since this was a systematic review of AEs following MT, effectiveness/efficacy of MT was not assessed. We neither performed meta-analysis nor risk of bias assessment. Subgroup analysis was done separating study designs by severity of AEs to assess if any specific type of massage would lead to more severe events.

\section{RESULTS}

Comprehensive search in seven electronic databases yielded a total of 12286 citations. Screening titles and abstracts identified 11348 references irrelevant to the review question; 938 full-text articles were retrieved for further evaluation. By using the pre-specified inclusion/ exclusion criteria, 60 studies were included (figure 1).

The discrepancies were discussed, and consensus was reached between the two reviewers. There were no residual discrepancies.

Included studies were published between 1991 and 2018, and were conducted in 11 countries including China $(n=1)$, France $(n=2)$, Germany $(n=1)$, India $(n=3)$, Iran $(n=3)$, Madagascar $(n=1)$, Malaysia $(n=1)$, Poland $(n=1)$, Russia $(n=2)$, Singapore $(n=1)$, Sweden $(n=1)$, Switzerland $(n=2)$, USA $(n=1)$ and UK $(n=2)$. Among 60 studies with a total population of $\mathrm{n}=3557,29$ studies $(n=1520)$ were single-arm experimental or case studies that received MT and 31 studies $(\mathrm{n}=2037)$ were studies with a comparator/control group, of which almost half $(n=972)$ have received MT and the rest $(n=1065)$ were controls with no MT. Gestational age (GA) in the preterm

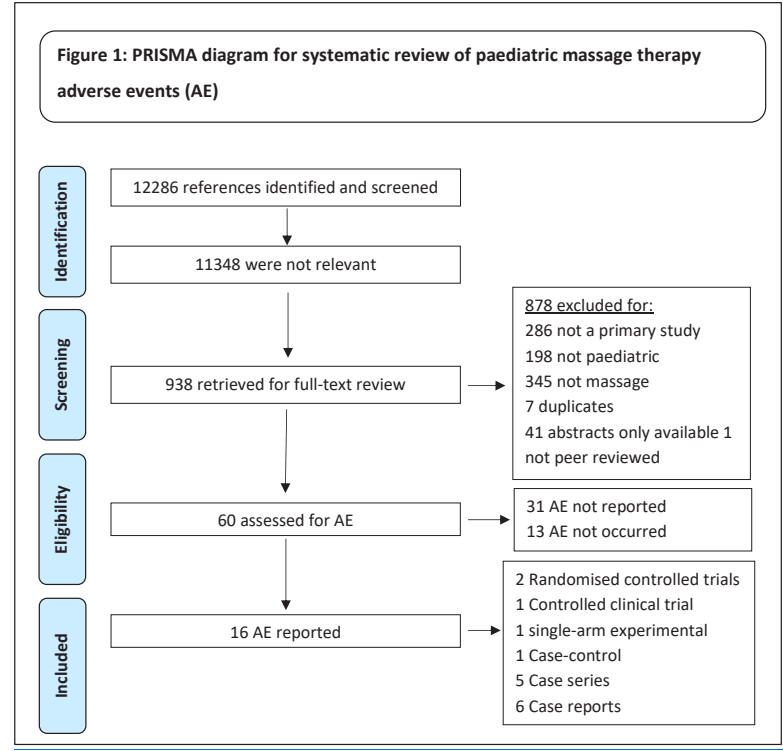

Figure 1 PRISMA diagram for systematic review of paediatric massage therapy adverse events (AEs).

infants having MT varied was from 23.5 to 37 weeks. Age of children ranged from 1 day to 18 years.

\section{Studies not reporting on $\mathrm{AE}$}

There were 13 studies (10 randomised controlled trials (RCTs), 1 controlled clinical trial (CCT), 2 single-arm experiments) that did not report if an $\mathrm{AE}$ occurred, or not, after receiving MT. Of total 878, 436 children $(0$ to 18 years) received MT for various reasons including infantile colic, childhood eczema, weight gain in preterm babies, soothing pain for heel stick, improving neurological diseases, and helping urinary tract and HIV infection.

\section{Reports of AEs}

Of 60 included studies, 16 (26.6\%) reported $\mathrm{AE}(\mathrm{s}), 31$ (51.6\%) did not mention if an AE occurred or not, and $13(21.6 \%)$ reported that no AE occurred. Figure 1 illustrates the PRISMA flow diagram. Of 16 studies $(n=438)$ reporting AEs, 13 were published in English, one in Russian and two in French. In total, 11 different types of AEs occurred in 64 individuals. Of 16 studies reporting an $\mathrm{AE}$, five did not state who performed the massage therapy. Of the 11 that reported, MT was provided by trained nurses $(n=2)$, parents/grandparents $(n=1)$, paramedic personnel $(n=1)$, nanny $(n=1)$, traditional massage practitioner $(\mathrm{n}=1)$ and trained massage practitioner $(n=5)$. In some cases, a nurse or trained massage practitioner started MT, and a parent continued the massage. None of the studies reported any AE associated with MT when it was provided by a licensed or registered massage therapist.

\section{Indirect AE}

One publication identified an indirect $\mathrm{AE}$, that is, a delay in diagnosis and/or treatment. A case report documented four children with Staphylococcus aureus osteomyelitis, which presented as upper arm swelling. ${ }^{44}$ The 
authors considered the use traditional MT for swelling a cause for delay in the diagnosis and treatment, leading to progression of the infection (grade 3 ).

\section{Risk of bias assessment}

Risk of bias was not assessed for two reasons: (1) the large majority of included studies (11 of 16) were case reports and case series, for which there is no universally accepted tool to assess bias; (2) with regards to RCTs, there is evidence that existing risk-of-bias tools are developed with efficacy as their main focus and that other factors should be considered for assessment of AEs. ${ }^{41}$ Until an appropriate tool is developed, we opt to not proceed with an assessment that may itself lead to bias. At present, there is no clear guidance on how to proceed with riskof-bias assessment on studies reporting AEs data. ${ }^{37} 41$ 45-48

\section{Studies not reporting on $\mathrm{AE}$}

There were 13 studies (10 RCTs, 1 CCT, 2 single-arm experiments) not reporting if an $\mathrm{AE}$ occurred, or not, after receiving MT. Of total 878, 436 children (0 to 18 years) received MT for various reasons including infantile colic, childhood eczema, weight gain in preterm babies, soothing pain for heel stick, improving neurological diseases, urinary tract infection and HIV infection.

\section{AEs and severity}

Serious AE (grades 4-5)

Five included studies reported 18 cases of serious AEs after MT. ${ }^{49-53}$

Seventeen preterm infants ( 15 females and two males) were diagnosed with intestinal volvulus without malrotation (VWM) after abdominal massage. The MT were usually performed 4-8 times per day by nurses to stimulate peristalsis in preterm (27-31 weeks gestational age) and extremely preterm $(>23.5$ and $<27$ weeks gestational age) infants. The intestinal volvulus occurred from 13 days to 52 days after birth. Four infants died (grade 5) and 13 survived after bowel resection surgery (grade 4). A retrospective case-control study done by Maas et at9 reports five extremely preterm infants (GA 24.4 weeks) with VWM. Each case was matched with five other preterm infants with similar birth weight, GA and birth year. Three of the five patients with volvulus died. Maas et al report that MT was not found to be a risk factor for the volvulus, as both cases and controls received massage similarly.

In addition, a serious AE also occurred in a 4-month-old female who had status epilepticus due to camphor intoxication, following abdominal massage with camphorcontaining lotion. She was hospitalised for 72 hours for uncontrolled seizures, where she was intubated, mechanically ventilated and given seizure treatment (grade 4) (table 2).

\section{Moderate AEs (grades 2-3)}

There was one non-randomised controlled trial (NRCT), ${ }^{54}$ two case series ${ }^{445}$ and four case reports ${ }^{32} 335657$ from 1994 to 2017 reporting on 27 children, aged from 1 day to 16 years. Those children experienced moderate AEs including infant mastitis/abscess, osteomyelitis, popliteal artery pseudoaneurysm, acute unilateral neurosensory hearing loss, scrotal haematoma and oxygen desaturation. The $\mathrm{NRCT}^{54}$ assessed physiological measurements including amplitude-integrated electroencephalography, oxygen saturation $\left(\mathrm{SaO}_{2}\right)$, pulse rate and cerebral blood flow in 39 preterm infants following whole body Shantal (stroking and rubbing whole body) massage by a therapist and the mother. They reported four cases of oxygen desaturation $(<85 \%)$ requiring withdrawal from the experiment (grade 2); no further details were provided. One case series ${ }^{55}$ described 15 cases of neonatal mastitis following repeated massage in 15 infants aged 6-48 days; all cases needed antibiotic therapy with or without abscess drainage (grade 3 ).

Three case reports of MT AE were also published: (1) a popliteal artery pseudoaneurysm after leg MT on an osteochondroma in a 16-year-old male ${ }^{33}$; (2) acute unilateral neurosensory hearing loss after MT on the neck and trapezius muscle in a 14-year-old male diagnosed with autonomic nervous system dysfunction ${ }^{57}$; (3) scrotal haematoma after traditional MT with a warm sand bag on hydrocoele of a 1-day-old baby boy. ${ }^{32}$ The first and third cases resolved after hospitalisation and appropriate surgery and second case resolved after intensive treatment plan at a hospital for 15 days and at home for 7 days (grade 3) (table 3).

\section{Mild AE (grade 1)}

Two RCTs ${ }^{58}$ described skin rashes after whole body massage with various oils (almond, mineral, coconut or safflower) examining the effects of MT on growth measurements (weight, height, etc) in 17 infants with age from 1 day to 3 days. These mild reactions occurred in $2.5 \%$ in the first ${ }^{58}$ and $6 \%$ in the second ${ }^{59}$ study populations; all resolved spontaneously without discontinuation of MT or the oils (grade 1). Two almost identical RCTs ${ }^{6061}$ examined the immunogenicity of mild rubbing massage on vaccination sites among 808 and 328 infants 2-6 months old, respectively. AEs included crying, anorexia, drowsiness, vomiting, irritability, fever, pain, redness and induration; all were mild and did not need an intervention except general health advice for vaccinated children (grade 1). Two single-arm experimental studies, one by Cullen et $a l^{62}$ described mild hyperactivity $(\mathrm{n}=1)$, and the other by Beaver ${ }^{63}$ reported increased blood pressure/heart rate and decreased transcutaneous oxygen saturation $(\mathrm{n}=8)$ following MT. One case report by Li $e t$ $a b^{64}$ described a mild skin bruising after a MT technique involving pinching skin. All these interventions needed minimal intervention for resolution (grade 1) (table 4).

\section{Unclassified AEs}

Due to insufficient information, we were unable to properly assess and rate the severity of $\mathrm{AE}$ reported by a NRCT. Goncharov ${ }^{65}$ assessed the effect of MT with a mixture of aromatic oils on central nervous system (CNS) 


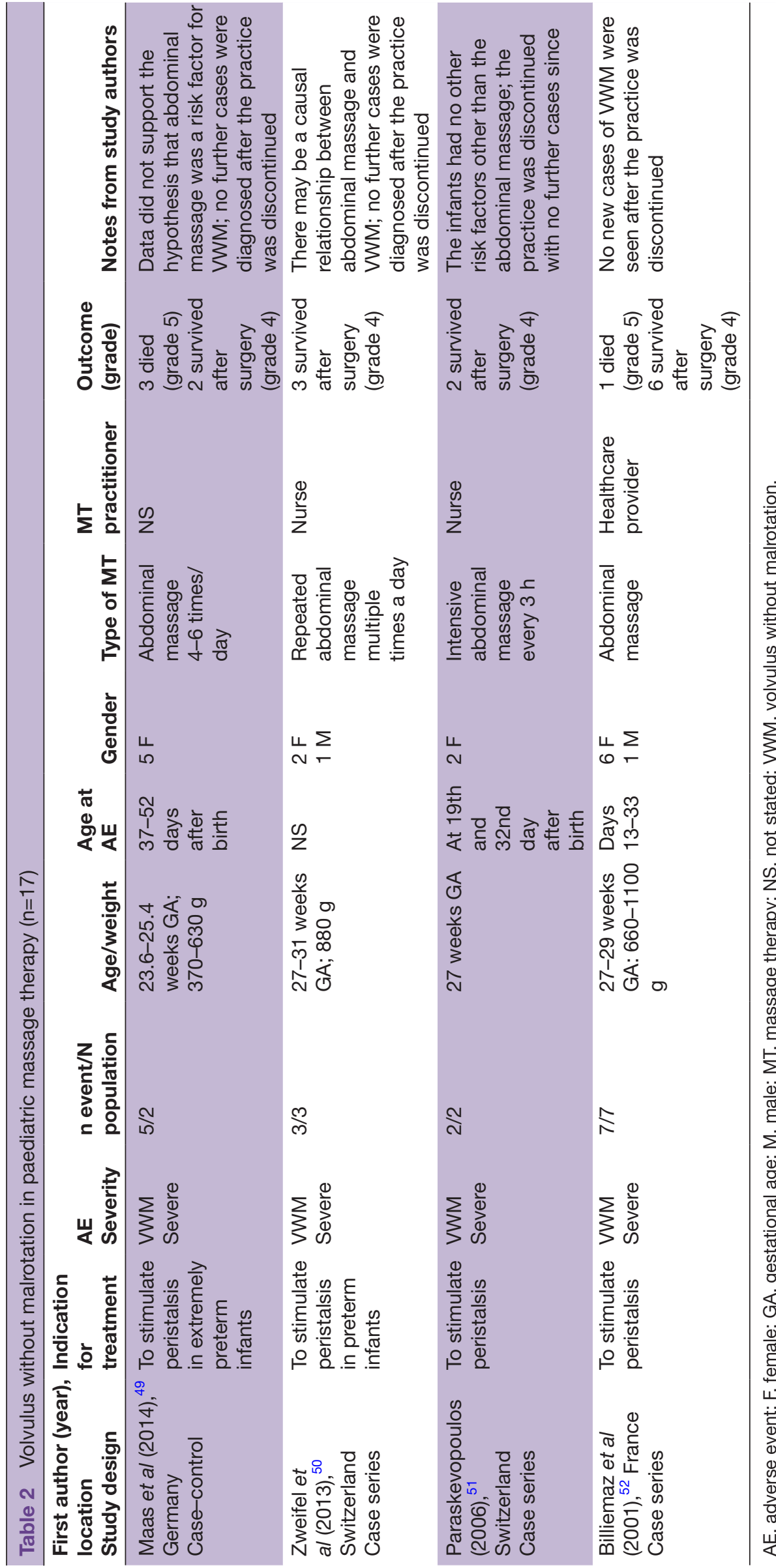




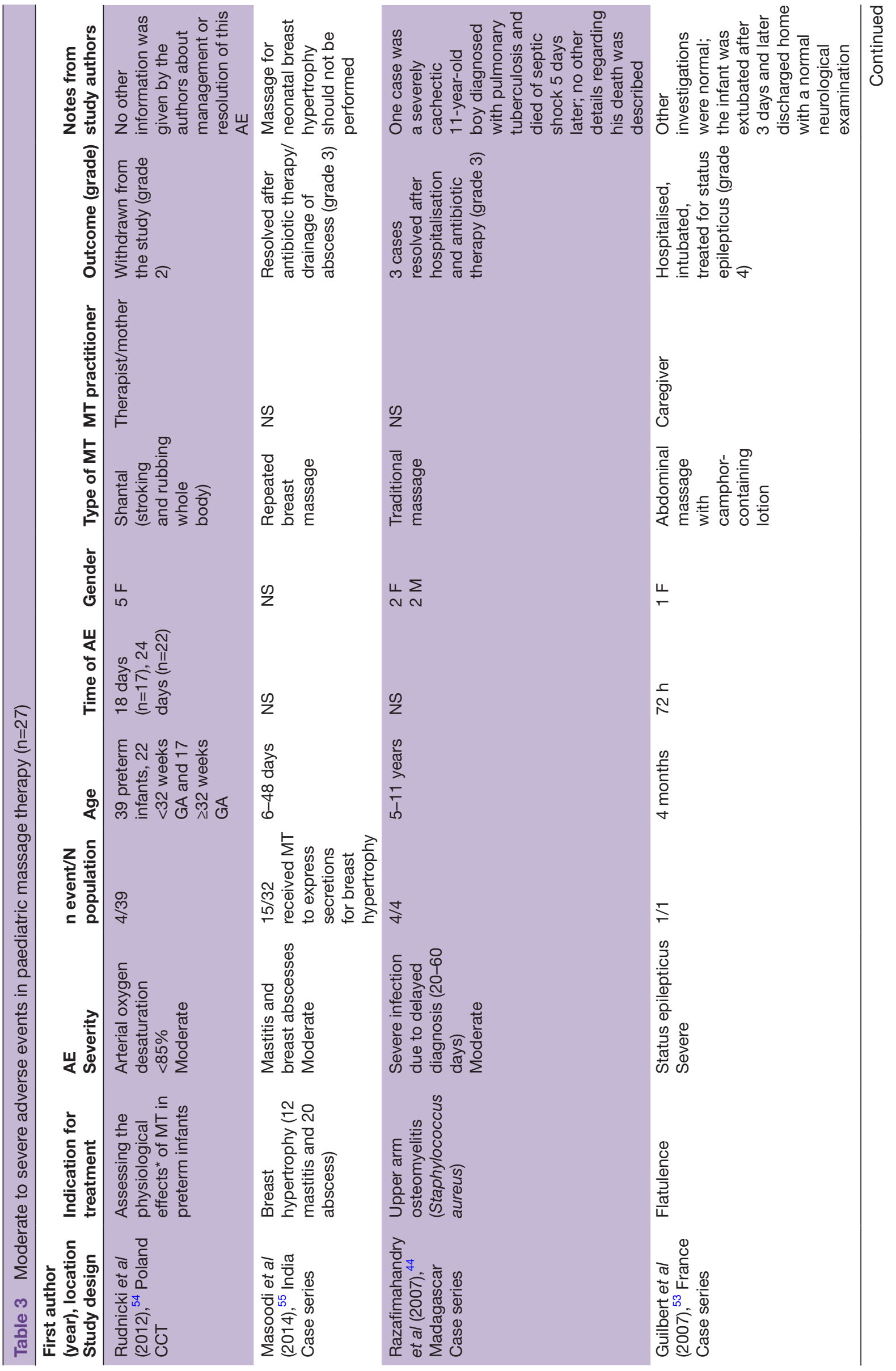




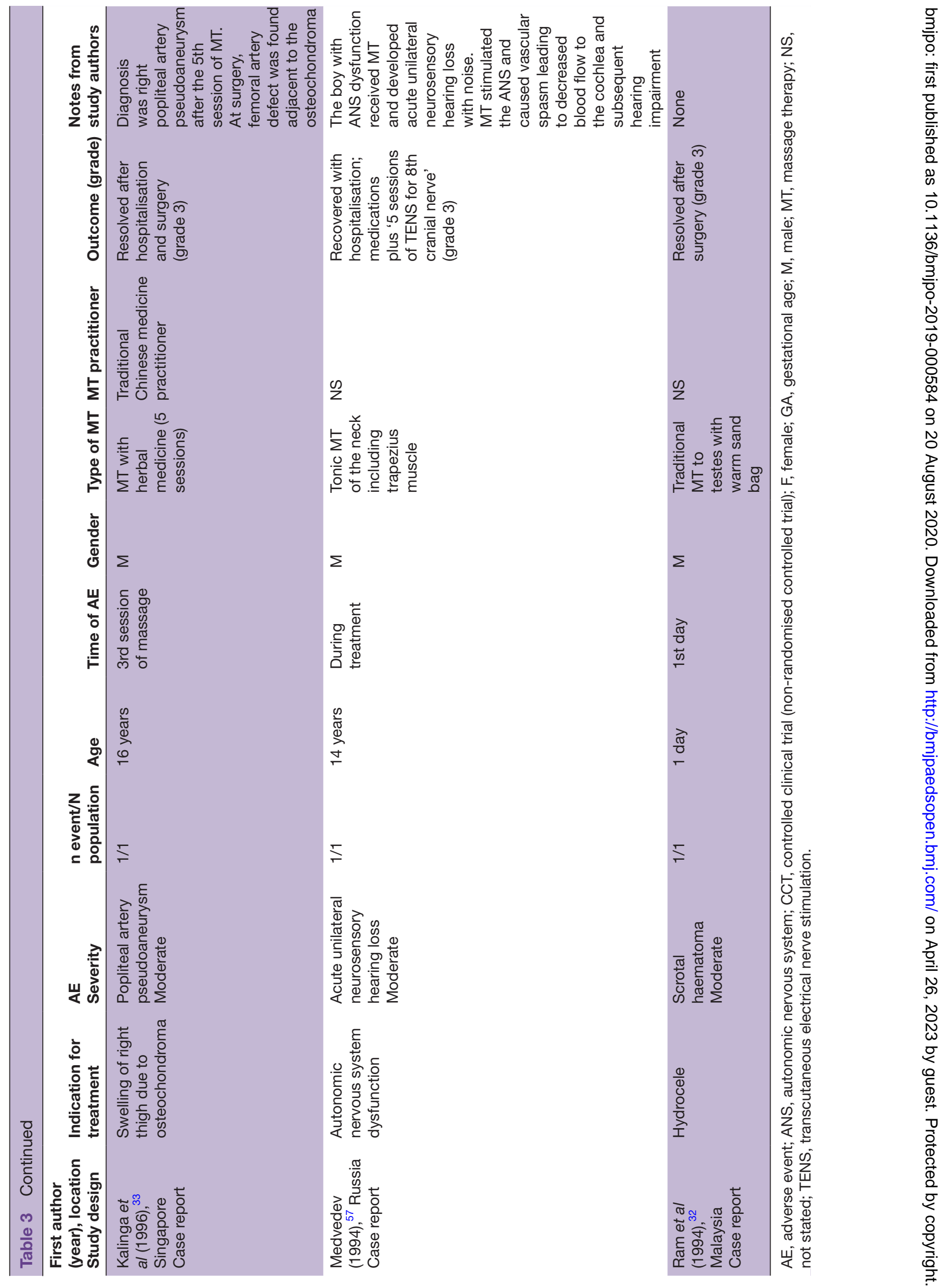




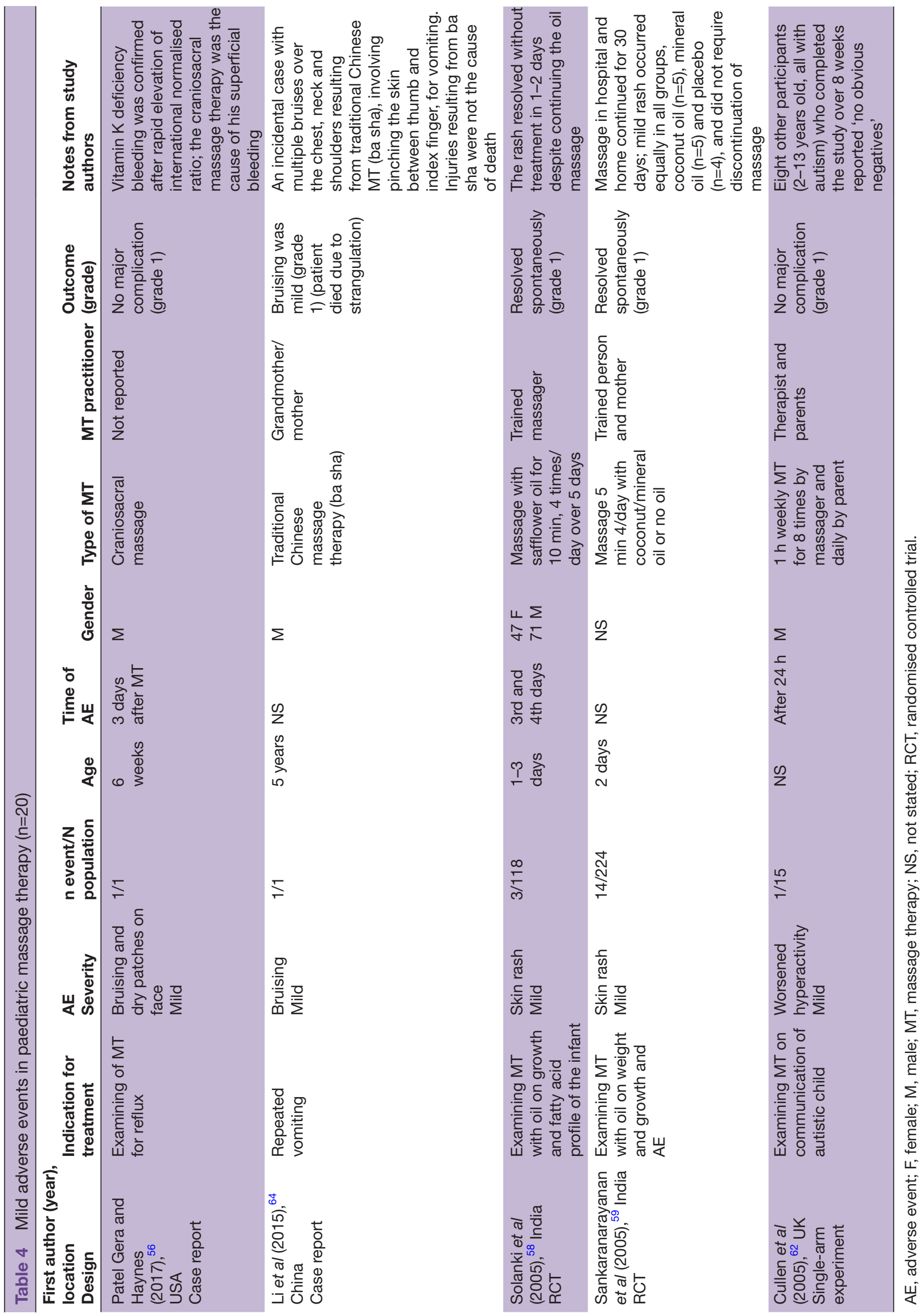


rehabilitation among 31 infants aged 4-18 months with perinatal hypoxic CNS injury. One child (age and sex not provided) developed an 'allergic reaction' (oil product not specified) and dropped out of the study (no further details were provided to allow for severity rating). The manuscript was written in Russian and author's contact information was not available.

\section{DISCUSSION}

To the best of our knowledge, this is the first systematic review to primarily assess AEs associated with paediatric MT.

After extensive search in multiple databases and including non-English studies, we identified 64 AEs associated with paediatric massage. These events were further classified into mild, moderate and severe by our team. Moderate events were the most frequently identified, closely followed by mild and severe AEs. Of serious AEs identified, abdominal massage to stimulate peristalsis in preterm infants was identified as being associated with multiple reports of VWM.

VWM is considered a rare event, often associated with preterm birth $(<30$ weeks GA) and low birth weight $(<1000 \mathrm{~g}) .^{49} 505266-69$ We identified 17 events of VWM in preterm infants on this review, mostly very low birth weight (VLBW). In five VWMs, the authors did not consider MT as a risk factor for the volvulus while for the remaining 12 events, MT was considered a risk factor by authors. ${ }^{49}$ The identified cases of VWM led to a routine change in their centres to avoid abdominal massage in preterm infants due the risk of volvulus. All the authors report that changing their practice to avoid abdominal massage in preterm neonates generated no further events of VWM in their centres. ${ }^{49}$ The large majority of the events reported in this review occurred in infants born at $<30$ weeks GA and weighed $<1000 \mathrm{~g}$, which may be a confounder since VLBW is considered a risk factor for VWM. Others have reported findings of VWM in preterm infants. Horsch $e t$ $a l$ have reviewed cases of volvulus in a surgical referral centre over 8 years in Germany and found three preterm infants with VWM, and of these, one received properistaltic abdominal massage. ${ }^{70}$ Yarkin $e t$ al, after reviewing 2 years of data from an epidemiological survey, identified that 12 of 15 cases of low birthweight $(<1500 \mathrm{~g})$ preterm infants with VWM had abdominal massages prior to the event, although due the uncontrolled study design, they were unable to determine abdominal massage as a direct risk factor. ${ }^{71}$ Horsch et al and Yarkin et al were not included in this review because they did not look into MT specifically. Several authors ${ }^{49} 707273$ have speculated on other risk factors for VWM, including immaturity of the intestine resulting in prolonged transit times and stool retention, use of continuous positive airway pressure or other intensive respiratory support, and female gender. Several of these risk factors were also identified in the included reports and it makes it difficult to assure causality of MT in the development of VWM.
MT has been studied in children, but with the main focus of assessing efficacy, very little has been reported on adverse events. ${ }^{18-21}$ 24-30 In contrast, adults report a wide range of AEs associated with massage, from mild events to severe, including cerebrovascular accidents, thromboembolism (renal, pulmonary), skin injury, leg ulcer, genitourinary injuries, disc herniation, soft tissue trauma, neurological compromise, spinal cord injury and dissection of the vertebral arteries, ${ }^{8435}$ although it is difficult to compare the different populations and comorbidities associated with each.

Similar to other studies ${ }^{74}$ this review reveals a lack of AEs reporting. The majority of included studies did not report if the intervention was associated with any $\mathrm{AE}$ or not, leading to significant reporting bias from the primary studies and carried into the review level, confirming that the true magnitude of AEs related to massage in paediatrics remains unknown.

\section{Strengths and limitations}

This review was inclusive in searching peer-reviewed publications in seven databases from inception onward, not limiting by language. We minimised subjective errors by independent duplicate screening, study selection and data extraction. This systematic review meticulously collected data from included studies and classified severities of AEs according to well-established criteria. We have incorporated to this review all relevant studies, including case reports, case series and clinical trials, in an effort to be comprehensive. In addition, we reported studies that reported if AEs occurred or not, whether they mentioned if AEs were assessed or not, except for case reports which were only included if an event was reported.

As any study, this review has limitations. The majority of the AEs were described in case series/reports. Although case studies are well-recognised sources of reports on severe, unusual and/or rare AEs, conclusions drawn from such sources are limited and subject to confounding factors. In addition, given the limited information and heterogeneity of the data reported in the included studies, it was not possible to identify any conclusive association between MT and specific AEs, except for ba sha massage which caused a characteristic bruising.

Risk of bias was not performed due to the nature of included studies.

\section{Clinical relevance of review findings}

The most significant review finding warranting clinical surveillance is the association between abdominal massage and VWM in preterm infants. There are several confounders impeding this review to define a causal relationship between neonatal abdominal massage and VWM, but the reports should be taken into careful consideration and abdominal massage should be considered with caution on this population. 


\section{CONCLUSIONS}

We were able to identify a range of AEs associated with MT use, from mild to severe. Unfortunately, the majority of included studies did not report if an AE occurred or not, leading to publication bias. This review reports an association between abdominal massage with VWM in preterm infants, and it is still to be defined if this is casual or not, but our findings warrant caution in the use of abdominal massage in preterm infants.

Correction notice This article has been corrected since it was published. Name for the first author has been corrected.

Acknowledgements We thank Susanne King-Jones for searching databases, library support and reviewing the manuscript; Katherine Smith, Sheena Sikora, Kerri Gladwin, Maleka Ramji and Namrata Hansraj for screening; Samaneh Khanpour Ardestani, Susanne King-Jones, Tatiana Kryuchkova, Natalia Liapounova Melissa Morelli-Lacroix, Derek Wang, Amy Wolgemuth, Hai Chuan Yu and Liliane Zorzela for translation of non-English papers. We thank Denise Adams for her contributions to the early development of this work.

Contributors SV, HJ and TD conceptualised and designed the study, reviewed and critically reviewed the manuscript for important intellectual content. MK, LZ and MF designed the data collection instruments, collected data, carried out the initial analyses, drafted the manuscript, and reviewed and revised the manuscript. All authors approved the final manuscript as submitted and agree to be accountable for all aspects of the work.

Funding The authors have not declared a specific grant for this research from any funding agency in the public, commercial or not-for-profit sectors.

Competing interests None declared.

Patient consent for publication Not required.

Provenance and peer review Not commissioned; externally peer reviewed.

Data availability statement Data are available on reasonable request. All data relevant to the study are included in the article or uploaded as online supplementary information. This is a systematic review and all data have already been published and/or presented in the review. No meta-analysis was done.

Open access This is an open access article distributed in accordance with the Creative Commons Attribution Non Commercial (CC BY-NC 4.0) license, which permits others to distribute, remix, adapt, build upon this work non-commercially, and license their derivative works on different terms, provided the original work is properly cited, appropriate credit is given, any changes made indicated, and the use is non-commercial. See: http://creativecommons.org/licenses/by-nc/4.0/.

ORCID iD

Liliane Zorzela http://orcid.org/0000-0002-6598-1642

\section{REFERENCES}

1 National Institutes of Health. Exploring the science of complementary and integrative health. National Center for Complementary and Integrative Health 2016 Strategic Plan, 2016.

2 Health Canada. Complementary and alternative health care: the other mainstream? Health Policy Research Bulletin 2003:1-48.

3 The College of Massage Therapists of Ontario. About massage therapy, 2019. Available: https://www.cmto.com/about-theprofession/about-massage-therapy/

4 The College of Massage Therapists of Ontario. About massage therapists in Ontario, 2019. Available: https://www.cmto.com/aboutthe-profession/

5 National Institutes of Health. Massage therapy: an introduction. National Center for Complementary and Integrative Health 2016 Strategic Plan [Internet], 2016. Available: https://nccih.nih.gov/ health/massage/massageintroduction.htm

6 National Institutes of Health. rMassage Therapy for Health Purposes. National Center for Complementary and Integrative Health 2016 Strategic Plan [Internet], 2016. Available: https://nccih.nih.gov/ health/massage/massageintroduction.htm

7 Sagar SM, Dryden T, Wong RK. Massage therapy for cancer patients: a reciprocal relationship between body and mind. Curr Oncol 2007;14:45-56.
8 Ernst E. The safety of massage therapy. Rheumatology 2003;42:1101-6.

9 National Institutes of Health. The use of complementary and alternative medicine in the United States. National Center for Complementary and Integrative Health 2016 Strategic Plan [Internet], 2007. Available: https://nccih.nih.gov/research/statistics/ 2007/camsurvey_fs $1 . h t m$

10 Adams D, Dagenais S, Clifford T, et al. Complementary and alternative medicine use by pediatric specialty outpatients. Pediatrics 2013;131:225-32.

11 Revuelta-Iniesta R, Wilson ML, White K, et al. Complementary and alternative medicine usage in Scottish children and adolescents during cancer treatment. Complement Ther Clin Pract 2014;20:197-202.

12 Adams D, Schiffgen M, Kundu A, et al. Patterns of utilization of complementary and alternative medicine in 2 pediatric gastroenterology clinics. J Pediatr Gastroenterol Nutr 2014;59:334-9.

13 Galicia-Connolly E, Adams D, Bateman J, et al. CAM use in pediatric neurology: an exploration of concurrent use with conventional medicine. PLoS One 2014;9:e94078.

14 Richmond E, Adams D, Dagenais S, et al. Complementary and alternative medicine: a survey of its use in children with chronic respiratory illness. Can J Respir Ther 2014;50:27-32.

15 Field T. Pediatric massage therapy research: a narrative review. Children 2019;6:78.

16 Guan L, Collet J-P, Yuskiv N, et al. The effect of massage therapy on autonomic activity in critically ill children. Evid Based Complement Alternat Med 2014;2014:1-8.

17 Nelson NL. Massage therapy: understanding the mechanisms of action on blood pressure. A scoping review. J Am Soc Hypertens 2015;9:785-93.

18 Field TM. Massage therapy effects. Am Psychol 1998;53:1270-81.

19 Bennett C, Underdown A, Barlow J. Massage for promoting menta and physical health in typically developing infants under the age of six months. Cochrane Database Syst Rev 2013;4:CD005038.

20 Field T, Diego M, Hernandez-Reif M. Preterm infant massage therapy research: a review. Infant Behav Dev 2010;33:115-24.

21 Beider S, Moyer CA. Randomized controlled trials of pediatric massage: a review. Evid Based Complement Alternat Med 2007;4:23-34.

22 Shin E-S, Seo K-H, Lee S-H, et al. Massage with or without aromatherapy for symptom relief in people with cancer. Cochrane Database Syst Rev 2016:CD009873.

23 Tsao JCl, Zeltzer LK. Complementary and alternative medicine approaches for pediatric pain: a review of the state-of-the-science. Evid Based Complement Alternat Med 2005;2:149-59.

24 Juneau AL, Aita M, Héon M. Review and critical analysis of massage studies for term and preterm infants. Neonatal Netw 2015;34:165-77.

25 Shipwright S, Dryden T. Paediatric massage: an overview of the evidence. Focus on Alternative and Complementary Therapies 2012;17:103-10.

26 Kulkarni A, Kaushik JS, Gupta P, et al. Massage and touch therapy in neonates: the current evidence. Indian Pediatr 2010;47:771-6.

27 Ireland M, Olson M. Massage therapy and therapeutic touch in children: state of the science. Altern Ther Health Med 2000;6:54-63.

28 Field T. Massage therapy for infants and children. J Dev Behav Pediatr 1995;16:105-11.

29 Moyer CA, Seefeldt L, Mann ES, et al. Does massage therapy reduce cortisol? A comprehensive quantitative review. J Bodyw Mov Ther 2011;15:3-14

$30 \mathrm{Li} \mathrm{X}$, Zhong Q, Tang L. A meta-analysis of the efficacy and safety of using oil massage to promote infant growth. J Pediatr Nurs 2016;31:e313-22.

31 Ernst E. Serious adverse effects of unconventional therapies for children and adolescents: a systematic review of recent evidence. Eur J Pediatr 2003;162:72-80.

32 Ram SP, Kyaw K, Noor AR. Haematoma testes due to traditional massage in a neonate. Trop Doct 1994;24:81-2.

33 Kalinga MJ, Lo NN, Tan SK. Popliteal artery pseudoaneurysm caused by an osteochondroma-a traditional medicine massage sequelae. Singapore Med J 1996;37:443-5.

34 Posadzki P, Ernst E. The safety of massage therapy: an update of a systematic review. Focus on Alternative and Complementary Therapies 2013;18:27-32.

35 Yin P, Gao N, Wu J, et al. Adverse events of massage therapy in pain-related conditions: a systematic review. Evid Based Complement Alternat Med 2014;2014:1-11. 
36 Ernst E, Barnes J. Methodological approaches to investigating the safety of complementary medicine. Complement Ther Med 1998;6:115-21.

37 Chou R, Aronson N, Atkins D, et al. AHRQ series paper 4: assessing harms when comparing medical interventions: AHRQ and the effective health-care program. J Clin Epidemiol 2010;63:502-12.

38 Zorzela L, Loke YK, loannidis JP, et al. PRISMA harms checklist: improving harms reporting in systematic reviews. BMJ 2016;352:i157.

39 Moher D, Liberati A, Tetzlaff J, et al. Preferred reporting items for systematic reviews and meta-analyses: the PRISMA statement. Int $J$ Surg 2010;8:336-41.

40 Golder S, Loke Y. Search strategies to identify information on adverse effects: a systematic review. J Med Libr Assoc 2009;97:84-92.

41 Higgins JPT, Thomas J, Chandler J, et al. Cochrane Handbook on systematic reviews of interventions version 6.0, 2019. Available: www.training.cochrane.org/handbook

42 CTCAE. Common terminology criteria for adverse events; version 4. US Department of Health and Human Services, National Institute of Health, National Cancer Institute, 2010.

43 Zorzela L, Mior S, Boon H, et al. Tool to assess causality of direct and indirect adverse events associated with therapeutic interventions. Curr Med Res Opin 2018;34:407-14.

44 Razafimahandry HJC, Rakoto-Ratsimba HN, Rakotoarisoa B, et al. Special features of humeral osteomyelitis in four children in Madagascar France. Institut de Medecine Tropicale, 2007: 275.

45 loannidis JPA, Evans SJW, Gøtzsche PC, et al. Better reporting of harms in randomized trials: an extension of the CONSORT statement. Ann Intern Med 2004;141:781-8.

46 Edwards IR, Aronson JK. Adverse drug reactions: definitions, diagnosis, and management. Lancet 2000;356:1255-9.

47 loannidis JP, Lau J. Completeness of safety reporting in randomized trials: an evaluation of 7 medical areas. JAMA 2001;285:437-43.

48 Loke YK, Derry S. Reporting of adverse drug reactions in randomised controlled trials - a systematic survey. BMC Clin Pharmacol 2001;1:3.

49 Maas C, Hammer S, Kirschner H-J, et al. Late-onset volvulus without malrotation in extremely preterm infants - a case-control-study. BMC Pediatr 2014;14:287.

50 Zweifel N, Meuli M, Subotic U, et al. Manufactured volvulus. Eur J Pediatr Surg 2013;23:234-7.

51 Paraskevopoulos EAR. Volvulus in two preterm infants: abdominal massage as a risk factor? Swiss Society of Neonatology 2006:1-10.

52 Billiemaz K, Varlet F, Patural H, et al. [Intestinal volvulus in extremely premature infants]. Arch Pediatr 2001;8:1181-4.

53 Guilbert J, Flamant C, Hallalel F, et al. Anti-flatulence treatment and status epilepticus: a case of camphor intoxication. Emerg Med $J$ 2007;24:859-60.

54 Rudnicki J, Boberski M, Butrymowicz E, et al. Recording of amplitude-integrated electroencephalography, oxygen saturation, pulse rate, and cerebral blood flow during massage of premature infants. Am J Perinatol 2012;29:561-6.

55 Masoodi T, Mufti GN, Bhat Jl, et al. Neonatal mastitis: a clinicomicrobiological study. J Neonatal Surg 2014;3:2.
56 Patel Gera M, Haynes A. Case 6: bruising and bleeding in a 6-weekold boy. Pediatr Rev 2017;38:144.

57 Medvedev EA. [Case of acute unilateral neurosensory hearing loss caused by massage of the trapezius muscle]. Vestn Otorinolaringol 1994;3:38-9.

58 Solanki K, Matnani M, Kale M, et al. Transcutaneous absorption of topically massaged oil in neonates. Indian Pediatr 2005;42:998.

59 Sankaranarayanan K, Mondkar JA, Chauhan MM, et al. Oil massage in neonates: an open randomized controlled study of coconut versus mineral oil. Indian Pediatr 2005;42:877.

60 Huang FY, Huang LM. Effect of local massage on vaccination: DTP and DTPA. Acta Paediatr Taiwan 1999;40:166.

61 Hsu CY, Huang LM, Lee CY, et al. Local massage after vaccination enhances the immunogenicity of diphtheria-tetanus-pertussis vaccine. Pediatr Infect Dis J 1995;14:567-72.

62 Cullen LA, Barlow JH, Cushway D. Positive touch, the implications for parents and their children with autism: an exploratory study. Complement Ther Clin Pract 2005;11:182-9.

63 Beaver PK. Premature infants' response to touch and pain: can nurses make a difference? Neonatal Netw 1987;6:13-17.

64 Li Z, Huan Z, Byard RW. Bruising caused by traditional Chinese massage therapy (Ba SHA) complicating the assessment of a case of fatal child abuse. J Forensic Leg Med 2015;36:49-51.

65 Goncharov OV. Massage with aromatic oils in complex rehabilitation of children with aftereffects of perinatal hypoxic lesions of the central nervous system Russian Federation, 2017. Available: http://ovidsp. ovid.com/ovidweb.cgi?T=JS\&PAGE=reference\&D=emed8\&NEWS = $N \& A N=17566172$

66 Yarkin Y, Maas C, Franz AR, et al. Epidemiological study on intestina volvulus without malrotation in VLBW infants. Arch Dis Child Fetal Neonatal Ed 2019;104:F415-88.

67 Mark S, Schlößer R, Gfroerer S, et al. Verfall des Allgemeinzustands eines Frühgeborenen. Monatsschrift Kinderheilkunde 2013;161:296-8.

68 Raherison R, Grosos C, Lemale J, et al. [Prenatal intestinal volvulus: a life-threatening event with good long-term outcome]. Arch Pediatr 2012;19:361-7.

69 Drewett M, Burge DM. Late-onset volvulus without malrotation in preterm infants. J Pediatr Surg 2009;44:358-61.

70 Horsch S, Albayrak B, Tröbs R-B, et al. Volvulus in term and preterm infants-clinical presentation and outcome. Acta Paediatr 2016;105:623-7.

71 Yarkin Y, Maas C, Franz AR, et al. Epidemiological study on intestinal volvulus without malrotation in VLBW infants. Arch Dis Child Fetal Neonatal Ed 2019;104:F415-8.

72 Berseth CL. Gestational evolution of small intestine motility in preterm and term infants. J Pediatr 1989;115:646-51.

73 Kargl S, Wagner O, Pumberger W. Volvulus without malposition-a single-center experience. J Surg Res 2015;193:295-9.

74 Anderson M, Choonara I. A systematic review of safety monitoring and drug toxicity in published randomised controlled trials of antiepileptic drugs in children over a 10-year period. Arch Dis Child 2010;95:731-8 